\title{
Relationship Between Seizures in Children with Maternal Anxious Levels at Pediatrics Intensive Care Unit
}

\author{
Mahirina Marjani", Martira Maddeppungeng, Idham Jaya Ganda, Dasril Daud \\ Department of Pediatrics, Hasanuddin University, Makassar, Indonesia \\ Email address: \\ mahirinamarjani@gmail.com (M. Marjani),martira711@yahoo.com (M. Maddeppungeng), dhamjaya_spa@yahoo.co.id (I. J. Ganda), \\ drdasri@gmail.com (D. Daud)
}

\section{To cite this article:}

Mahirina Marjani, Martira Maddeppungeng, Idham Jaya Ganda, Dasril Daud. Relationship Between Seizures in Children with Maternal Anxious Levels at Pediatrics Intensive Care Unit. American Journal of Health Research. Vol. 3, No. 3, 2015, pp. 156-160.

doi: 10.11648/j.ajhr.20150303.18

\begin{abstract}
Introduction: Seizure is an emergency condition that makes mother or the care taker being anxious. The anxious of parents frequently denied where as psychological problems both acute and chronic could be happened intervention as a holistic approach to the patient and her family. Objective: To analize the correlation between seizure in children hospitalization in Pediatrics Intensive Care Unit (PICU) with the maternal anxious levels. Methods: A cross-sectional study was done and the data were collected from the 29-day-old to 18 years children treated in PICU of Dr. Wahidin Sudirohusodo Hospital, Makassar from April through September 2014. Total of samples comprised 133 children were devided into two groups: 58 children in the seizure group and 75 other in the not seizure group. The maternals anxious levels are based on the HARS (Hamilton anxious rating scale) score. Results: The study revealed there is a significant correlation between the seizure in children with maternal anxious levels as shown by the Odds Ratio (OR) value of 6.286 CI95\% $=2.912-13.569$ with p value of 0.000 (p $<0.01$ ), and the mean, median, maximum and minimum values of HARS score were higher in seizure group: the values being $31.5: 26.02$, 30.5: 26, and 20-50: 18-24 respectively with $\mathrm{p}=0.000(\mathrm{p}<0.01)$. Conclusion: Severe anxious frequency evidences in maternals with children who had seizure were higher than in children without seizure, either of the HARS score of maternals.
\end{abstract}

Keywords: Seizure, Anxious Degree, Hamilton Anxious Rating Scale

\section{Introduction}

Seizures are common clinical manifestation in the emergency room. There are $4 \%$ to $10 \%$ of children under age of 16 years had experienced seizure once during their life. Seizure is an important sign of a neurological disorder. This situation is an emergency. Seizures may be simple; it can stop itself and no need for further treatment, or an early symptom of serious illness, or likely to be an epilepticus status. In the form of epilepticus status, seizures patients' especially child requires intensive care as much as $15 \%$ to $25 \% .1$

Medical service not only aims to restore the patient physical health but also keeping the emotional and physical condition of patient be comfortable, but the rapid progress in medical field has not been accompanied by similar progress in terms of the humanitarian aspects of patient care. 2 The process of medical care in hospitals often ignore the psychological aspects of giving rise to a variety of psychological problems for parents whose children are treated, including ignored the anxious in the elderly, causing a variety of psychological problems whether it is acute or chronic; therefore this case need to be done.

The cause of maternals' anxious with seizures in children among others concerned life-threatening children and anxiety impact of seizure disorders such intelligence can lead to disability. 3 Anxiety disorder is a condition characterized by feelings of fear accompanied by somatic complaints that are shown as hyperactivity of the autonomic nervous system and non-specific symptoms which are common and often is a normal emotion. 4

Different people have different perspectives in the face of the same problem, and so are their responses. In addition to the intensive care room treatment, action or procedure that requires surgery is one of the factors that can aggravate mothers 'anxiety. Parent's anxiety problems, especially the mother, is important, because an illness child will also be able to feel the anxiety of their parents; therefore, the children could also become anxious that can aggravate their disease. Mother and child psychological relationship occurs 
while still a baby in the womb. Mother plays a role in meeting the child's psychological and physiological needs. 5 Other impacts of excessive anxious are the onset of panic can occur even in the form of neurogenic shock in the mother may even show a decrease in the potential health, such as chronic disorders. 4

Parental anxious can be assessed in several ways. One of the most common scoring systems used was the Hamilton anxious rating scale (Hars) or often abbreviated as HAM - A. HM - A uses a series of questions with answers that must be filled by an experienced clinician who has been associated with a particular of patient's condition. There are 14 symptoms that appear in individuals with anxious. Each item was given 5 levels observed a score of 0 to 4.6 Previous studies by Kartikahadi obtained that the levels of mothers anxious of child treated in PICU was higher than those who are treated in wards.7 Similar study is also obtained by Board et al. according to Kartikahadi result study.8 Study on maternal anxious levels with seizures in children has never been done in Makassar; therefore, this study is expected to be used for the development of anxious containment procedures of maternal in children with seizures. The purpose of this case was to analyze the relationship between seizures in children with maternal anxious levels at pediatrics intensive care unit.

\section{Materials and Methods}

A cross-sectional study was done to evaluate the levels of maternal anxious in patients with and without seizures treated in the pediatric intensive care. We conducted this study at Dr. Wahidin Sudirohusodo hospital, from April through September 2014. This study was approved by the Ethics and Industry Research Committee of the hospital and written informed consent was obtained from the patients' parents or legal guardian following full and detail explanation regarding the study's protocol.

The studies samples are obtained based on the sequence of the entry in the hospital (consecutive random sampling) and we obtained 133 patients after exclude 10 patients. Samples are affordable throughout the population who met the inclusion and exclusion criteria. The inclusion criteria are children aged 29 days to 18 years, experienced the seizure for the first time in PICU, and biological mother of the samples' studied. The exclusion criteria are maternal with psychiatric disorders and maternal with a single parent status.

Then, the patiernts were divided into 2 groups; children with seizures and children of non seizures. At the same time, we measured the degree of maternal anxious sufferers by the Hamilton anxious rating scale in each group. The degree of maternal anxious scores were grouped into $<14$ is not anxious, the score of $14-27$ is mild/ moderate anxious, and a score of 28-56 is a severe anxious.

Data were obtained by recording the child's age, sex, and diagnosis of childhood diseases, maternal age, maternal education, family income, number of children, and the order of the child. Then we assess the maternal anxious scores. Further analyses of the data based on the appropriate statistical methods include univariate and bivariate analyzes. The study process can be seen in the figure 1 below:

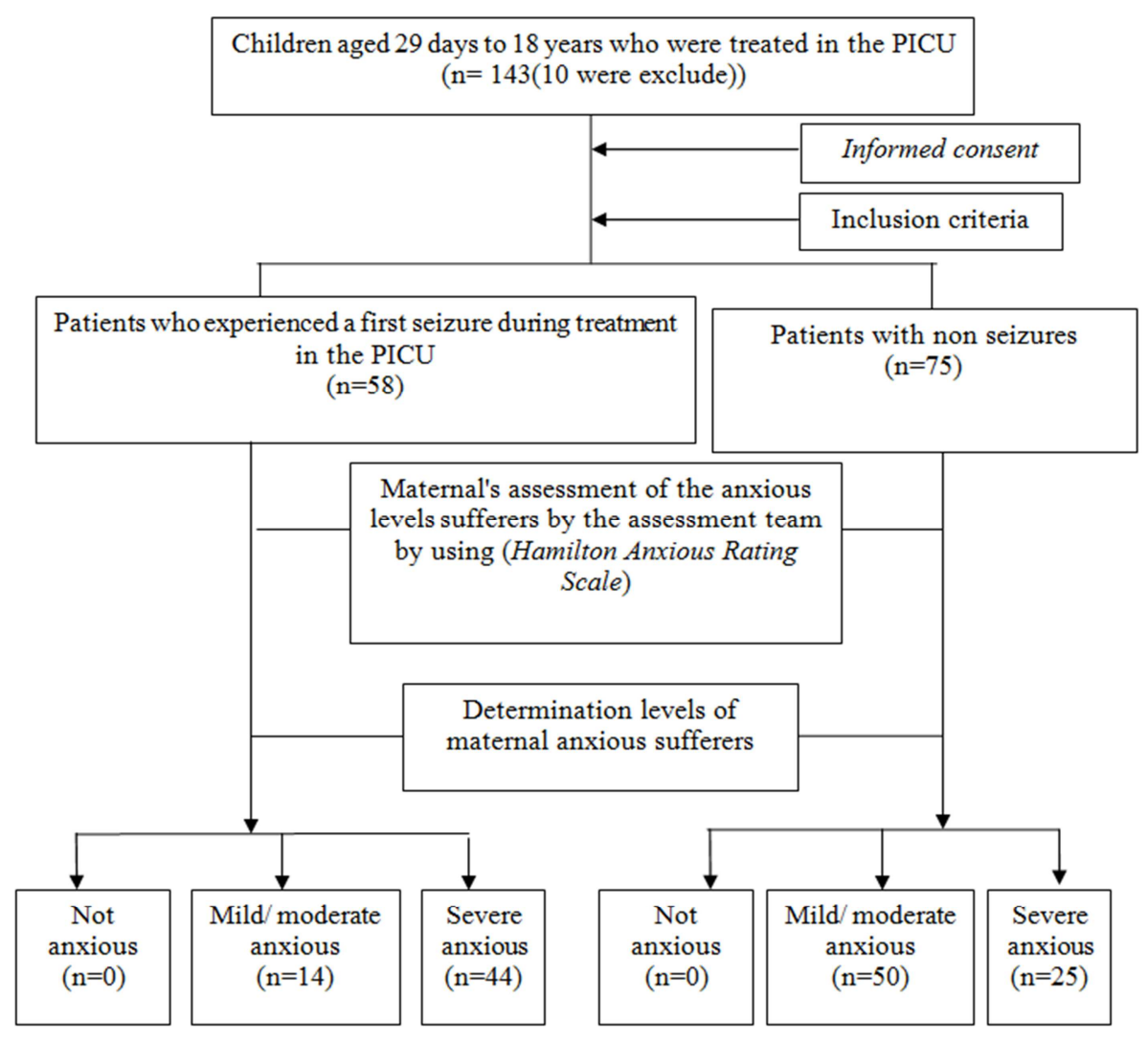

Figure 1. Study flow scheme. 


\section{Results}

Table 1. Study sample characteristics.

\begin{tabular}{|c|c|c|c|}
\hline \multirow{2}{*}{$\begin{array}{l}\text { Sample } \\
\text { characteristics }\end{array}$} & \multicolumn{2}{|c|}{ Maternal anxious levels } & \multirow{2}{*}{ Total } \\
\hline & Mild/ moderate & Severe & \\
\hline \multicolumn{4}{|l|}{ Sex } \\
\hline Male & $33(41.8 \%)$ & $46(58.2 \%)$ & $79(100 \%)$ \\
\hline Female & $31(57.4 \%)$ & $23(42.6 \%)$ & $54(100 \%)$ \\
\hline \multicolumn{4}{|l|}{ Group } \\
\hline Seizure & $14(24.1 \%)$ & $44(75.9 \%)$ & $58(100 \%)$ \\
\hline Not Seizure & $50(66.7 \%)$ & $25(33.3 \%)$ & $75(100 \%)$ \\
\hline \multicolumn{4}{|l|}{ Aged } \\
\hline$<6$ years & $44(45.8 \%)$ & $52(54.2 \%)$ & $96(100 \%)$ \\
\hline$>6$ years & $20(54.1 \%)$ & $17(45.9 \%)$ & $37(100 \%)$ \\
\hline \multicolumn{4}{|l|}{ Illness diagnosis } \\
\hline Infection & $36(44.4 \%)$ & $45(55.6 \%)$ & $81(100 \%)$ \\
\hline Non infection & $28(53.8 \%)$ & $24(46.2 \%)$ & $52(100 \%)$ \\
\hline \multicolumn{4}{|l|}{ Maternal aged } \\
\hline$<40$ years & $54(50.0 \%)$ & $54(50.0 \%)$ & $108(100 \%)$ \\
\hline$>40$ years & $10(40.0 \%)$ & $15(60.0 \%)$ & $25(100 \%)$ \\
\hline \multicolumn{4}{|l|}{ Child order } \\
\hline 1 child & $40(56.3 \%)$ & $31(43.7 \%)$ & $71(100 \%)$ \\
\hline$>1$ child & $24(38.7 \%)$ & $38(61.3 \%)$ & $62(100 \%)$ \\
\hline \multicolumn{4}{|l|}{ Among of child } \\
\hline Only child & $28(59.6 \%)$ & $19(40.4 \%)$ & $47(100 \%)$ \\
\hline$>1$ child & $36(41.9 \%)$ & $50(58.1 \%)$ & $86(100 \%)$ \\
\hline \multicolumn{4}{|c|}{ Maternal education } \\
\hline Non scholar & $59(50.9 \%)$ & $57(49.1 \%)$ & $116(100 \%)$ \\
\hline Scholar & $5(29.4 \%)$ & $12(70.6 \%)$ & $17(100 \%)$ \\
\hline \multicolumn{4}{|l|}{ Family income } \\
\hline$<150$ dollars & $17(38.6 \%)$ & $27(61.4 \%)$ & $44(100 \%)$ \\
\hline$>150$ dollars & $47(52.8 \%)$ & $42(47.2 \%)$ & $89(100 \%)$ \\
\hline
\end{tabular}

Table 1 show the study characteristics samples. There are 79 patients $(59.4 \%)$ male and $54(40.6 \%)$ female. Fifty eight children (43.6\%) with seizures and $75(56.4 \%)$ of non seizures, while the children aged $<6$ years were 96 patients $(72.2 \%)$ and $>6$ years are 37 patients $(27.8 \%)$. Patients with infectious disease diagnosis are $81(60.9 \%)$, whereas a noninfectious disease is $52(39.1 \%)$. Maternal age less than 40 years was 108 samples $(81.2 \%)$, and the rest $>40$ years as 25 samples $(18.8 \%)$. The first child was 71 patients $(53.4 \%)$, while, as the second child or more are 62 patients (46.6\%). Patients as a single child are $47(35.3 \%)$, and not as single child are 86 patients $(64.7 \%)$. Non scholar mothers were 116 samples $(87.2 \%)$, and 17 are scholar mother $(12.8 \%)$.

Table 2. Relationship of the seizure and non seizure group with the maternal anxious levels.

\begin{tabular}{llll}
\hline \multirow{2}{*}{ Groups } & \multicolumn{2}{l}{ Maternal anxious levels } & \multirow{2}{*}{ Total } \\
\cline { 2 - 3 } & Severe & Mild/ moderate & \\
\hline Seizure & $44(75.9 \%)$ & $14(24.1 \%)$ & $58(100 \%)$ \\
Not Seizure & $25(33.3 \%)$ & $50(66.7 \%)$ & $75(100 \%)$ \\
Total & $69(51.9 \%)$ & $64(48.1 \%)$ & $133(100 \%)$ \\
\hline
\end{tabular}

Chi-square $\left(X^{2}\right)=23.696 \mathrm{df}=1 \mathrm{p}=0.000 \mathrm{OR}=6.286 \mathrm{IC} 95 \%=2.912$ 13.569

Table 2 shows the analyses relationship of seizures and not seizure in children with the maternal anxious levels, it showed a highly significant difference between both group with $\mathrm{p}=$ $0.000(\mathrm{p}<0.01)$. OR (odds ratio) value $=6.286$ with $95 \%$ IC value of 2.912 to 13.569 . This means that the frequencies of maternal anxious levels of severe seizure in children are 6.28 times comparing to maternal in not seizures group.

Table 3 shows the correlation analyses of the child's age, sex, diagnosis of childhood diseases, maternal age, number of children, the order of the child, maternal's education, and families income to the maternal anxious levels showed no significant difference between both groups of children aged $<6$ years and children $>6$ years on maternal anxious levels with $\mathrm{p}>0.05$.

Table 4 shows the analyses of the relationship between seizures and Hars score that indicates the average value, median, and range of Hars scores in children with seizures and not seizures. The Hars scores are higher in the group of seizures than the not seizures group with significancy value of 0.000 . This indicates that there are very significant differences between the Hars scores to the both group with a value of $\mathrm{p}<0.01$.

Table 3. Moderator variable relationship with maternal anxious levels.

\begin{tabular}{|c|c|c|c|c|}
\hline \multirow{2}{*}{ Variable } & \multicolumn{2}{|c|}{ Maternal anxious levels } & \multirow{2}{*}{ Total } & \multirow{2}{*}{ p value } \\
\hline & Mild/ moderate & Severe & & \\
\hline \multicolumn{5}{|l|}{ Sex } \\
\hline Male & $33(41.8 \%)$ & $46(58.2 \%)$ & $79(100 \%)$ & \multirow{2}{*}{$\mathrm{p}=0.076 \mathrm{IC} 95 \%=0.264-1.072$} \\
\hline Female & $31(57.4 \%)$ & $23(42.6 \%)$ & $54(100 \%)$ & \\
\hline Group & & & & \multirow{3}{*}{$\begin{array}{l}\mathrm{p}=0.000 \\
\mathrm{IC} 95 \%=2.912-13.569\end{array}$} \\
\hline Seizure & $14(24.1 \%)$ & $44(75.9 \%)$ & $58(100 \%)$ & \\
\hline Non Seizure & $50(66.7 \%)$ & $25(33.3 \%)$ & $75(100 \%)$ & \\
\hline \multicolumn{5}{|l|}{ Aged } \\
\hline$<6$ years & $44(45.8 \%)$ & $52(54.2 \%)$ & $96(100 \%)$ & \multirow[t]{3}{*}{$\mathrm{p}=0.395 \mathrm{IC} 95 \%=0.336-1.540$} \\
\hline$>6$ years & $20(54.1 \%)$ & $17(45.9 \%)$ & $37(100 \%)$ & \\
\hline \multicolumn{4}{|c|}{ Illness diagnosis } & \\
\hline Infection & $36(44.4 \%)$ & $45(55.6 \%)$ & $81(100 \%)$ & \multirow[t]{2}{*}{$\mathrm{p}=0.290$ IC95\% $=0.341-1.381$} \\
\hline Non infection & $28(53.8 \%)$ & $24(46.2 \%)$ & $52(100 \%)$ & \\
\hline \multicolumn{5}{|l|}{ Maternal age } \\
\hline$<40$ years & $54(50.0 \%)$ & $54(50.0 \%)$ & $108(100 \%)$ & \multirow[t]{2}{*}{$\mathrm{p}=0.367 \mathrm{IC} 95 \%=0.619-3.633$} \\
\hline$>40$ years & $10(40.0 \%)$ & $15(60.0 \%)$ & $25(100 \%)$ & \\
\hline \multicolumn{5}{|l|}{ Child order } \\
\hline 1 child & $40(56.3 \%)$ & $31(43.7 \%)$ & $71(100 \%)$ & \multirow{2}{*}{$\mathrm{p}=0.042 \mathrm{IC} 95 \%=1.021-4.088$} \\
\hline$>1$ child & $24(38.7 \%)$ & $38(61.3 \%)$ & $62(100 \%)$ & \\
\hline
\end{tabular}




\begin{tabular}{|c|c|c|c|c|}
\hline \multirow{2}{*}{ Variable } & \multicolumn{2}{|c|}{ Maternal anxious levels } & \multirow{2}{*}{ Total } & \multirow{2}{*}{ p value } \\
\hline & Mild/ moderate & Severe & & \\
\hline \multicolumn{5}{|l|}{ Among of child } \\
\hline Only child & $28(59.6 \%)$ & $19(40.4 \%)$ & $47(100 \%)$ & \multirow{2}{*}{$\mathrm{p}=0.051 \mathrm{IC} 95 \%=0.993-4.215$} \\
\hline$>1$ & $36(41.9 \%)$ & $50(58.1 \%)$ & $86(100 \%)$ & \\
\hline Maternal education & & & & \multirow{3}{*}{$\begin{array}{l}\mathrm{p}=0.098 \\
\mathrm{IC} 95 \%=0.823-7.500\end{array}$} \\
\hline Non scholar & $59(50.9 \%)$ & $57(49.1 \%)$ & $116(100 \%)$ & \\
\hline Scholar & $5(29.4 \%)$ & $12(70.6 \%)$ & $17(100 \%)$ & \\
\hline$<150$ dollars & $17(38.6 \%)$ & $27(61.4 \%)$ & $44(100 \%)$ & \multirow{2}{*}{$\begin{array}{l}\mathrm{p}=0.124 \\
\mathrm{IC} 95 \%=0.270-1.174\end{array}$} \\
\hline$>150$ dollars & $47(52.8 \%)$ & $42(47.2 \%)$ & $89(100 \%)$ & \\
\hline
\end{tabular}

Table 4. Relationship of seizure and not seizure groups with the HARS score.

\begin{tabular}{lll}
\hline HARS score & Seizure & Not Seizure \\
\hline Mean & 31.15 & 26.02 \\
Median & 30.50 & 26.00 \\
Minimum- Maximum & $20-50$ & $18-34$ \\
\hline
\end{tabular}

Mann-Whitney $\mathrm{U}=1071.0 \mathrm{p}=0.000$

\section{Discussion}

This study shows the relationship between seizures in children with the maternal anxious levels treated in pediatric intensive care unit. The advantages of sampling with a wide range of age are getting a large number of samples and greater in sample variation. In our study, the children are grouped by age $<6$ years and $>6$ years. Based on the age distribution of children aged 0-6 years and $>6$ years, at the age of $0-6$ years is the maternal school stage where the development of the senses and the acquisition of basic knowledge are under the maternal care in the household environment, while $>6$ years of age are the school stage in formal education. ${ }^{9}$ The results shows that the statistical analyses has no significant difference between the the child age with the maternal anxious levels. This is similar with a study by Kartikahadi and Merikangas, which states that there is no significant difference in the age of the child to the maternal anxious levels with children treated in PICU and wards. ${ }^{7,10}$

Relationship analyses of seizures in children with maternal anxious levels showed a highly significant difference in Hars scores between the maternal of both groups (seizures and not seizure) with OR 6.28. This is consistent with the study by Board et al. who reported the severity of disease experienced by the child has a positive relationship to the symptoms of stress suffered by their mother. ${ }^{8}$ In contrast to the study by Youngblut, which states that the parents reaction of children who are treated in the PICU and stressors experienced by them did not correlate with the severity of the disease. ${ }^{11}$

In our study, the sequence test to the child and maternal anxious levels showed a significant difference between both of them, but after further analyses of the sequence relationship of children to seizures showed no significant difference in the statistical analyses. This study was also carried out the test between sex, the diagnosis of diseases in children, number of children, family income, and maternal education on their anxious levels. We obtained the same result with the study by Kartikahadi, that there are no significant difference among the test. ${ }^{7}$
In this case we found also the constraints on anxious scores we are used for (Hars scores), which is the assessment scores were not assessed at the same time so it takes a lot of time during the assessment. Some questions in the scores are subjective; therefore, it can lead to different interpretations. The strength of this study is with a larger sample using a cross-sectional design that easy and economical, it can be used as the data for prospective cohort studies evaluating the effect of seizures on the maternal anxious levels as a holistic approach for the patient.

Based on the results of the study, the frequency of maternal severe anxious was higher in children who experienced seizures than children who did not have seizure, either in maternal anxious scores. According to our study, we suggest the necessity of parents counseling, especially the mother, who have a strong emotional relationship with her child, so the mother anxious levels can be reduced which in turn have a positive impact on child care. More study are need to be conducted with a prospective cohort design to assess the long-term psychological impact on maternal with a children experienced seizures, should be considered to use other measurement tools to assess the maternal anxious levels objectively.

\section{References}

[1] Kania N. Seizures in children and the handling of seizures in children. Bandung. 2007; 1-6.

[2] Pinel JP. Anxiety disorders. El Rais H, biopsychology. $7^{\text {th }}$ edition. Pearson Education. Boston. 2009; 587-90.

[3] PPDGJ III, Ministry of Health, General Directorate / Medical Services. In: Neurotic Disorders, Somatoform Disorders and Stress-related Disorders. First edition. 1993; 179-81.

[4] Shudy M. Impact of pediatric critical illness and injury on families: a systematic literature review. Pediatrics. 2006; 118: S203-18.

[5] Pujianti D. Child interaction in families with emotional intelligence. Nutrition study programs and family resource. IPB. 2008; 10-5.

[6] Gabbard GO. Anxious disorders: Psychodinamic psychiatry in clinical practice. American Psychiatric Publishing. Virginia. 2005; (2) 49-81.

[7] Kartikahadi L. Comparison of maternal anxious scores in pediatric intensive care unit and general ward parents in Paediatrica Indonesiana. 2012; (52): 95-8. 
[8] Board R, Ryan-Wenger N. Long-term effects of PICU hospitalization on families with young children. Heart Lung. 2002; (3): 53-66.

[9] Commenius JM. Didactica magna in opera didactica omnia. London Scolar Press. 1970
[10] Merikangas KR. Anxious disorders: Epidemiology. Lippincot Williams \& Wilkins. Philadelphia. 2005; 1720-28.

[11] Youngblut JM, Shiao SP. Child and family reaction during and after pediatric ICU hospitalization: a pilot study. Heart Lung. 1992; 22: 46-54. 